\title{
SUCCESSFUL TREATMENT OF A PERFORATED ROKITANSKY-CUSHING ULCER
}

\author{
BY
}

\author{
T. A. SALE \\ From the General Hospital, Singapore
}

(RECEIVED FOR PUBLICATION FEBRUARY 27, 1956)

Peptic ulceration in infancy and childhood is now a well established clinical entity. The condition, its incidence and the pathological findings have been well described by writers such as Bird, Limper and Mayer (1941) and Guthrie (1942). Most early descriptions of the condition were usually an account of the necropsy findings. As a result of the greater publicity given to the condition, surgeons in general, and paediatricians in particular, began to look for the disease in life, and there is now a large volume of literature indicating the success with which this search has been rewarded. In the very lethal complication of perforation of the ulcer into the general peritoneal cavity, it has now been shown that successful operations can be performed even in very young babies. In these young babies, however, the problem has not been entirely solved and a mortality rate of about $90 \%$ (Rubell, Leix and Clelland, 1952) or $70^{\circ}$ (Bird et al., 1941) has been reported. There is, nevertheless, a slowly increasing number of successful operations being performed in these patients. Thus, Selinger (1932) described the successful closure of a perforated stomach ulcer in a 3-month-old baby.

Bird and his colleagues successfully closed a perforated duodenal ulcer in a $34 \frac{1}{2}$-hour-old baby. Léger, Ricard, Léonard and Piette (1950) were successful in a 6-day-old baby. To these may be added the case of Brink and Keyzer (1952) in a 1-day-old baby with a perforated duodenal ulcer and that of Schwartz and Halberstam (1943), in which the patient was 11 months old. In all these cases the disease had arisen as a single specific entity. They were examples of what Gross (1953) has called the primary peptic ulcer of childhood. The secondary peptic ulcers arise as complications of other diseases. These include the ulcers arising in association with burns (Curling, 1842), with sepsis, marasmus, general toxaemia or as a complication of intracranial disease. This last type of ulcer has been called the Rokitansky-Cushing ulcer. It would seem from the literature that this ulcer, especially when perforated, is a pathological finding at necropsy. Gross (1953) only mentions their occurrence. The rarity of this condition and the failure to find a record of a similar case have prompted this paper.

\section{Case Report}

The patient, a 10-month-old male Chinese baby, was admitted to the General Hospital, Singapore, on February 3, 1955. There was a history of two days" pyrexia associated with a slight cough. He had had convulsive attacks for one day. His temperature was $103=\mathrm{F}$. on admission. The anterior fontanelle was bulging. The child was having fits, mainly on the right side, although all limbs were involved. He was comatose. The head circumference was $19 \frac{1}{2}$ in. The pupils were dilated and did not react to light. Turbid fluid under pressure was removed from the spinal theca. No organisms were grown on culture. The child was treated with penicillin, sulphadiazine and luminal. The temperature was settling on February 7, when the baby vomited blood. Next morning the abdomen was distended, tense and tender. There was marked dyspnoea and the child was cyanosed. A radiograph of the chest was negative, but one of the abdomen (Fig. 1) showed a large collection of free gas under the diaphragm. A stomach washout was given, but there was no blood in the washings.

The child was put into an oxygen tent and a slow blsod transfusion of $250 \mathrm{ml}$. given. The history, signs and radiological appearance were those of a perforated peptic ulcer with bleeding. In spite of the poor condition of the patient, it was decided that laparotomy was the only chance of cure. The anaesthetic, open ether with full and constant oxygenation, was administered by Dr. F. W. Pais. The abdomen was quickly opened through a right split rectus muscle incision. The peritoneum ballooned out before it was opened and air hissed out on opening it. There was a very little perforation on the superior border of the first part of the duodenum. It was about the size of a large pin-head and had a small amount of fibrin around it with a marked inflammatory reaction in the vicinity. The edges of the hole were quite soft. The perforation was well demonstrated by gently squeezing the second part of the duodenum when a small bead of bile could be seen issuing from the hole. The defect was closed by a fine catgut suture and the omentum tied 


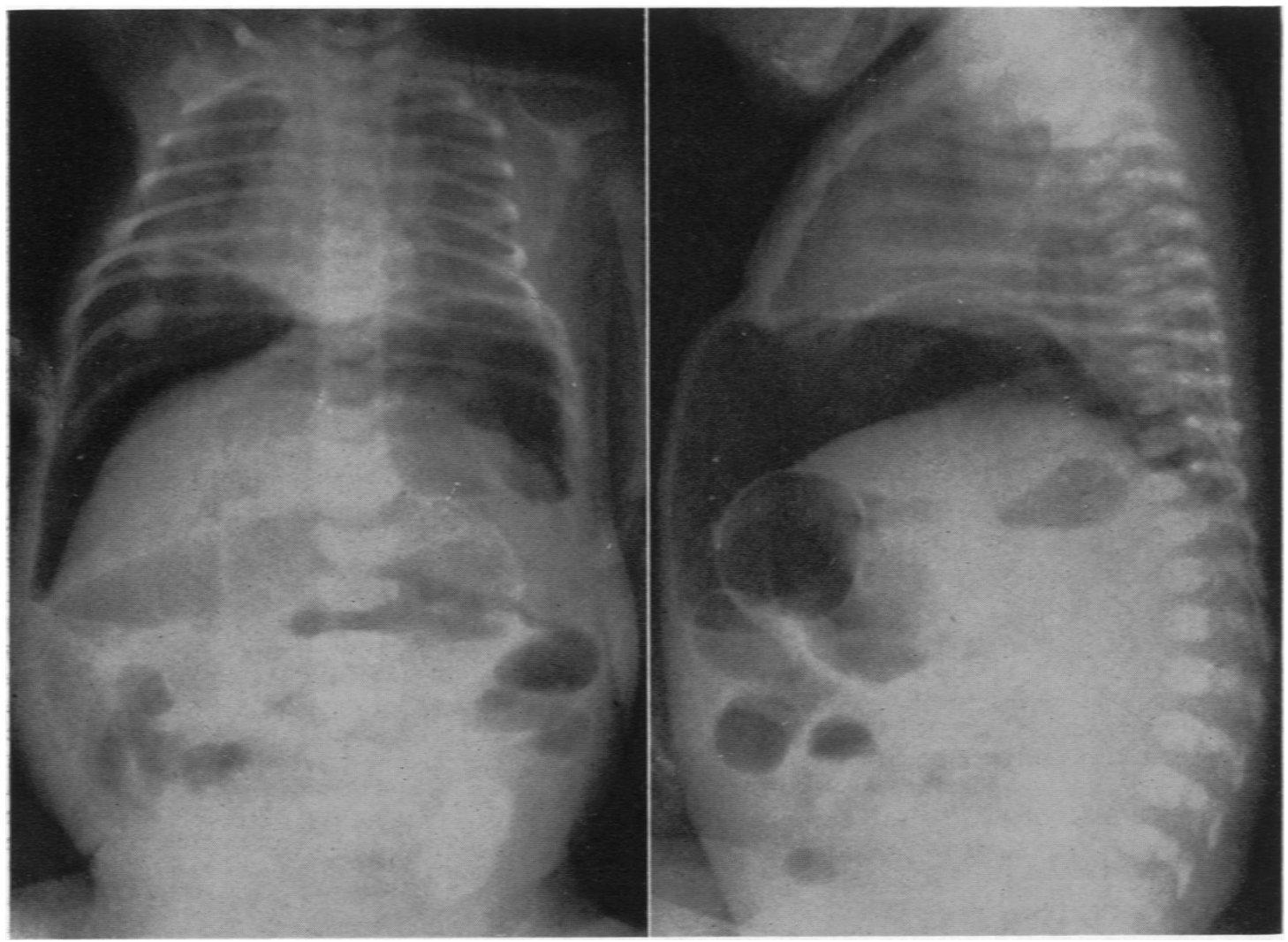

FiGs. 1 AND 2.-Radiographs showing gas under the diaphragm.

over this. A small drain was inserted and the abdomen closed. Post-operatively gastric suction was maintained for 24 hours and intravenous fluids given. There was very little drainage from the drainage tube. The convalescence was straightforward and eminently satisfactory. The sutures were removed on February 16. The child's cerebral condition slowly improved. He was listless for a time and had a right lateral rectus palsy. This had completely cleared when he was discharged on February 26.

\section{Discussion}

According to Cushing (1932), it was Rokitansky who was the first to draw attention to the association of the development of peptic ulceration in patients with brain and meningeal lesions. Cushing (1932) in his classical paper on the subject drew attention to the fact that in 11 cases of cerebral pathology there was at necropsy ulceration in the upper gastrointestinal tract. It is for this reason that the type of ulcer described in the above case history is called a Rokitansky-Cushing ulcer in the same way that an ulcer following burns is known so well by the term Curling`s ulcer. Ivy, Grossman and Bachrach (1951) state that it has been demonstrated beyond doubt that haemorrhagic erosions and acute ulcers of the stomach and duodenum occur in association with intracranial damage or disease. They point out, however, that it has not been shown that these acute digestive tract lesions depend on disturbances in the diencephalon and much less in some particular area within that division of the brain. Schlumberger (1951) found 10 such lesions incidentally in 251 consecutive necropsies. They were all acute, and were in the fundus and along the greater curvature of the stomach. He found that perforation was not common in this condition in children, and noted that when it did occur it was more common in gastric than in duodenal ulcers. They may be multiple. The theories postulated for the occurrence of these ulcers have been well described by Cushing and others and Schlumberger mentions that there may be a humoral factor such as the adrenocorticotrophic hormone involved in their production. Cook, Hartmann, Sarnoff and Beren- 
berg (1951) have shown that peptic ulceration can occur in association with acute bulbar poliomyelitis.

Perforated peptic ulceration in children as a solitary lesion is not at all uncommon. It occurs in infancy and even in the neonatal period, and there are many references to this fact in the literature. Most perforations in the early days of infancy are fatal. All writers stress the importance of early diagnosis and treatment. Pointers to the diagnosis are shock, vomiting, haematemesis and/or melaena. Cyanosis and tachycardia are early signs (Wright and Scott, 1950) until the fifth day of the illness when clinical peritonitis becomes evident. It appears evident, therefore, that when a child is suffering from some intracranial disease and exhibits the features described, the possibility of there being an acute peptic ulcer should be borne in mind and steps taken to confirm or allay one's suspicions. As Gellis (1952) writes, 'patients with bulbar paralysis, meningitis and encephalitis as well as brain tumours, should be watched carefully for ulcer complication. Prompt institution of therapy might, in such cases, prove life-saving'. This case report bears out this prophesy in no uncertain manner.

Cases of perforation in the newborn and young babies have been successfully treated by operation as I have shown. These patients stand operation well, provided it is early enough. In these days of antibiotics, prompt operation can save the life of a child even when suffering from such a serious disease as meningitis.

This baby had an undoubted meningitis, even though the causative organism was not isolated: the bulging fontanelle, the turbid cerebrospinal fluid, convulsions, etc., were unmistakable evidence. In the course of a cure for this condition, the baby had a haematemesis and then a perforation of an undoubted ulcer. This, therefore, is a case of a Rokitansky-Cushing ulcer, and as such should have been fatal. Conservative measures such as those advocated by Taylor (1946) would in my opinion have proved unavailing. The tenseness of the abdomen, and the child's great respiratory embarrassment made it imperative to relieve the tension caused by the intraperitoneal air. Further, at operation there was no attempt by surrounding structures to seal off the perforation, whilst the omentum, so very small in this 10 -month-old baby, was far removed from the site of the leak. Again, the child's general condition was deteriorating in spite of intragastric suction and intravenous therapy, and laparotomy was considered to be the only means of trying to save his life. Bleeding and perforation are a definite indication for operation in adults and should be an indication for operation in children.

The anaesthetic used was sufficient to give adequate relaxation and at the same time to ensure complete oxygenation. The approach by means of a split rectus incision is one I have used in many Rammstedt operations and led straight to the perforation. The manner of closing the perforation is one I have used so many times in adults and $I$ have never had cause to worry about the possibility of obstructing the duodenum. I had in mind Ladd's advice on this danger in children. I have never hesitated to insert a suture in a suspected duodenal tear while doing a Rammstedt operation. I felt that the closure had been complete and thought that there would have been great difficulty trying to suture the omentum over the gap in view of the site of the perforation. Schwartz and Halberstam (1943) sutured the ulcer in their successful case and in the follow-up noted only a slight four-hour residue. The ulcer should be closed in the most convenient manner which is certain to be efficient, quickest to perform, and will cause the least trauma to this most important anatomical area.

\section{Summary}

The successful closure of a perforated Rokitansky-Cushing ulcer in a 10-month-old baby is reported, and the problem discussed with references to the literature on the subject.

My thanks are due to Dr. Quah Quee Guan for referring this case to me, and to Professor D. E. C. Mekie for allowing me to see and treat this case, and to the Director of Medical Services, Singapore, for permission to publish this report.

\section{REFERENCES}

Bird, C. E., Limper, M. A. and Mayer, J. M. (1941). Ann. Surg.. $114,526$.

Brink, E. ten and Keyzer, J. L. (1952). Maandschr. Kindergeneesk. $20,108$.

Cook, C. D., Hartmann, J. R., Sarnoff, S. J. and Berenberg. W. (1951) Pediatrics, 7, 415.

Curling, T. B. (1842). Med.-chir. trans., 25, 260.

Cushing, H. (1932). Surg. Gynec. Obstet., 55, 1.

Gellis, S. (Ed.) (1952). Year Book of Pediatrics, p. 172. Chicago.

Gross, R. E. (1953). The Surgery of Infancy and Childhood. Philadelphia.

Guthrie, K. J. (1942). Archives of Disease in Childhood, 17, 82.

Ivy, A. C., Grossman, M. I. and Bachrach, W. H. (1950). Peptic Llcer. Philadelphia.

Léger, J. L., Ricard, P. M., Leonard, C. and Piette, C. (1950). Lin. med. Can., 79, 1277

Rubell, E. B., Leix, F. and Clelland, R. A. (1952). J. Pediat. 40, 337.

Schlumberger, H. G. (1951). A.M.A. Arch. Path., 52, 43

Schwartz, S. A. and Halberstam, C. A. (1943). Arch. Pediat., 60,185 .

Selinger, J. (1932). Ann. Surg., 96, 204.

Wright, L. T. and Scott, B. E. (1950). J. Pediat., 37, 905.

Taylor, H. (1946). Lancet, 2, 441. 